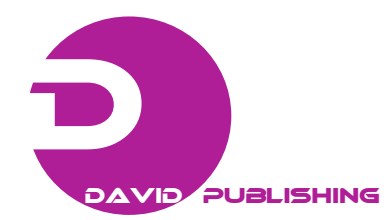

\title{
Behavior of Liposcelis bostrychophila (Psocoptera:Liposcelididae) Under Dark Condition
}

\author{
Goro Kimura* $^{1}$, Akihiro Miyanoshita ${ }^{2}$ and Tsutomu Tanikawa ${ }^{1}$ \\ 1. Technical Research Laboratory, IKARI Corporation 579 Chibadera, Chuo-ku, Chiba 260-0844, Japan \\ 2. National Food Research Institute, NARO 2-1-12 Kannondai, Tuskuba, Ibaraki 305-8642, Japan \\ *Corresponding author's e-mail: giken@ikari.co.jp
}

\begin{abstract}
Psocids (Psocoptera) are major pests of stored products. Psocids belonging to the genus Liposcelis increasingly infest stored products because of the measurable weight losses, allergic reactions, health concerns, and contamination of food materials with fecal material and exuviae. Many studies have been conducted on management of psocid, but few detailed studies have been conducted on their biology. The objective of our study was to evaluate the dispersal ability of the Liposcelis bostrychophila by release and recapture method. After two weeks of release, almost psocids were recaptured by sticky traps within $1.0 \mathrm{~m}$ from release point. One psocid was recaptured $4.0 \mathrm{~m}$ distance from release point. No psocids were recaptured $5.0 \mathrm{~m}$ distance from release point. In addition, the results of capture were not changed after four weeks of release. These results suggest that psocids do not disperse positively under dark condition.
\end{abstract}

Key words: Behavior, Psocoptera: liposcelididae, allergy, health hazard, dark condition. 